\title{
The Research on Credit Risk of Local Government Bonds Based on KMV Model: A Case Study of Shanghai Government Bonds
}

\author{
Wenjie Xing \\ School of Economics, Sichuan University, Chengdu 610000, China. \\ xingwenjie52@163.com
}

\begin{abstract}
Keywords: local government bonds; KMV model; default probabilities; credit rating; information disclosure.
\end{abstract}

\begin{abstract}
Based on the background of the independent issuance of local governments in China, this paper uses the modified KMV model to carry on the empirical analysis to measure the credit risk of the bond. This paper analyzes and predicts the guaranteed fiscal revenue and its growth rate and volatility of the issuance of Shanghai government bonds in the future, and then forecasts the safe issue-volume of different period bonds. From the point of view of default probabilities, the credit risk of Shanghai government bonds is very small, but it will increase with the increase of the scale of issuance. This paper finally proposes some policy suggestions based on the research results.
\end{abstract}

\section{1. 文献综述}

地方政府负债的主要原因主要有体制性原因, 政策性原因和债务管理原因。在体制性原 因方面, 张成 (2011) 研究了我国地方政府债务风险的现状、原因, 认为落后不彻底的财政 体制改革是造成债务风险的重要原因。张莉（2010）认为造成地方债务风险加大的直接原因 在于地方政府财权和事权的严重不匹配, 深层次的原因在于 1994 年的分税制改革, 地方政府 投融资平台的担保状况不佳则是地方政府债务的助推剂。赵全厚（2011）认为工业化和城市 化的加速发展是地方政府性债务产生的基本原因，另外，政府间财政关系改革的不彻底、行 政考核机制不健全等也助长了地方政府负债融资的冲动。贾康（2010）则从政策方面分析了 地方政府债务产生的原因，如地方政府普及义务教育、执行粮食购销政策等被动负担的债务。 在地方政府债务管理方面, 周佳嵋等 (2011) 认为债务资金的筹集与使用缺乏科学性和规范 性，地方政府只好借新债还旧债，形成了债务“滚雪球”效应。

随着地方政府债务规模的迅速扩张, 我国学者在地方政府信用风险评价方面也展开积极 探索。李江波 (2010) 在 KMV 模型中加入了 Knight 因子 $\lambda$, 对北京市 1978-2009 年的安全发 债规模进行测度, 违约概率变成一个区间, 且当 $\lambda>0$ 时, 违约概率区间会随着 $\lambda$ 增大而增大, 揭示了除信用风险之外的不确定性。杨胜刚等 (2011) 以湖南省为例, 运用 GA-PS0 研究地方 政府的信用等级, 确定地方政府的信用担保比例, 将担保资金代入 KMV 模型, 最终确定地方 政府合理的发债规模。李腊生等 (2013) 把地方政府债务可在政府间转移这一特点引入 KMV 模 型, 测算了 18 个省市 2011-2013 年需要偿还的债务额及相应的违约概率, 得出了我国地方政 府不存在经济上的违约风险, 而存在道德风险的结论。马德功等 (2015) 运用 KMV 模型, 对 四川省 2013 和 2014 年债券到期债务进行了推算, 并运用改进的 KMV 模型, 对 2013 年和 2014 年四川省地方政府债务进行压力测试, 推算了四川省 2013 和 2014 年三年期和五年期的债券 违约概率和安全的发债规模。王学凯、黄瑞玲（2015）利用 GM $(1,1)$ 模型预测地方财政收入, 并利用 KMV 模型对政府债务违约风险进行了测度, 认为地方政府隐性债务风险总体可控, 但 是在地区间存在明显差异。张海星、靳伟风（2016）考虑了财政政策变动对财政收入的影响, 引入虚拟变量, 利用修正的 KMV 模型, 预测大连市不同期限市政债券的安全发债规模。 


\section{KMV模型测度地方政府债券信用风险的基本原理}

KMV 模型是将期权定价理论应用于预测企业违约概率的信用风险检测模型，其基本思想 是：首先计算出公司资产的市场价值和公司资产价值的波动率, 其次, 根据现在的资产价值 确定未来的公司资产预期价值, 然后通过公司负债计算出违约点, 最后算出预期资产价值下 降至违约点的违约距离, 最后通过违约距离得到违约概率的映射。

随着主权债务危机的频繁发生, 这一模型不只限于评估企业的违约风险, 也开始被用于 评估政府主体的债务违约风险。由于我国地方政府债券的发行刚刚起步, 相关的债务历史数 据十分有限, 而许多模型的应用需要大量的统计样本做支撑, 因此, KMV 模型可测度单个资 产风险、所需历史数据较少、对债务主体资产变化反应敏捷等特点满足研究我国地方政府债 券安全发行规模的需求。

KMV 模型需要修正后才可测度地方政府债券的信用风险。采用地方政府的财政收入为地 方债券担保, 当地方政府债券到期时, 如果用于偿还债券的地方财政收入足以覆盖债券本息, 地方政府将偿还债务, 赎回财政收入, 反之地方政府债券存在违约可能。通过对 KMV 模型进 行改进, 用于担保的地方财政收入替代企业资产市值, 地方财政收入的增长率的均值和地方 财政收入的波动性替代企业资产收益率和资产市值的波动性, 则到期时需偿还的债券即为地 方政府债券的价值。

假设地方财政收入服从如下随机过程:

$$
\mathrm{A}_{\mathrm{t}}=\mathrm{f}\left(\mathrm{Z}_{\mathrm{t}}\right)
$$

其中 $A_{t}$ 为 $t$ 时刻地方政府财政收入, $Z_{t}$ 为随机变量, $\mathrm{f}$ 为某一函数,

地方政府财政收入服从马尔科夫随机过程, 可用维纳过程表示:

$$
\mathrm{d} \mathrm{A}_{\mathrm{t}}=\mu \mathrm{A}_{\mathrm{t}} \mathrm{dt}+\sigma \mathrm{Adz}_{\mathrm{t}}
$$

其中 $\mu$ 与 $\sigma$ 分别为地方财政收入的增长率与波动率, $\mathrm{dz}_{\mathrm{t}}$ 表示维纳增量。

由式 (2) 得, t时地方财政收入:

$$
\mathrm{A}_{\mathrm{t}}=\mathrm{A}_{0} \exp \left[\left(\mu-\frac{1}{2} \sigma^{2}\right) \mathrm{t}+\sigma \sqrt{\mathrm{t}} \mathrm{Z}_{\mathrm{t}}\right]
$$

其中, $\mathrm{A}_{0}$ 为 $\mathrm{t}=0$ 时的地方财政收入, $\mathrm{Z}_{\mathrm{t}} \sim N(0,1)$ 。此时称地方财政收入服从对数正态分布。 当 $\mathrm{t}=\mathrm{T}$ ( $\mathrm{T}$ 为发行债券的期限) 时, 由式 (3) 得 $\ln \mathrm{A}_{\mathrm{t}}$ 期望和方差分别为:

$$
\begin{aligned}
& E\left[\ln A_{T}\right]=\ln A_{0}+\mu T-\frac{1}{2} \sigma^{2} T=\frac{1}{n-1} \sum_{i=1}^{n-1} \ln A_{0} \times \frac{A_{i+1}}{A_{i}} \\
& \operatorname{var}\left[\ln A_{T}\right]=\sigma^{2} T=\frac{1}{n-2} \sum_{i=1}^{n-1}\left(\ln \frac{A_{i+1}}{A_{i}}-\frac{1}{n-1} \sum_{i=1}^{n-1} \ln \frac{A_{i+1}}{A_{i}}\right)^{2}
\end{aligned}
$$

根据（4）式和（5）式, 可得城市财政收入增长率 $\mu$ 和波动率 $\sigma$ :

$$
\mu=\left[\frac{1}{n-1} \sum_{i=1}^{n-1} \ln \frac{A_{i+1}}{A_{i}}+\frac{1}{2} \sigma^{2} T\right] / T \quad \sigma=\sqrt{\left[\frac{1}{n-2} \sum_{i=1}^{n-1}\left(\ln \frac{A_{i+1}}{A_{i}}-\frac{1}{n-1} \sum_{i=1}^{n-1} \ln \frac{A_{i+1}}{A_{i}}\right)^{2}\right] / T}
$$

按照修正的KMV模型, 当地方政府债券到期时 ( T为到期日), 若服从对数正态分布的地方政 府财政收入At小于到期应偿还的债券面值Bt, 政府就会违约, 则地方政府债券的违约条件可 表示为 $\mathrm{At}<\mathrm{Bt}$ 。违约概率用 $\mathrm{p}$ 表示，则根据（1）式，

$$
\mathrm{p}=\mathrm{P}\left[\mathrm{A}_{\mathrm{T}}<\mathrm{B}_{\mathrm{T}}\right]=\mathrm{P}\left[\mathrm{f}\left(\mathrm{Z}_{\mathrm{T}}\right)<\mathrm{B}_{\mathrm{T}}\right]=\mathrm{P}\left[\mathrm{Z}_{\mathrm{T}}<\mathrm{f}^{-1}\left(\mathrm{~B}_{\mathrm{T}}\right)\right]
$$

若 $Z_{\mathrm{t}} \sim N(0,1)$, 即服从标准正态分布时, 则地方政府债券的违约率为: 


$$
\begin{aligned}
\mathrm{p}=\mathrm{P}\left[\mathrm{Z}_{\mathrm{T}}<\mathrm{f}^{-1}\left(\mathrm{~B}_{\mathrm{T}}\right)\right] & =\mathrm{N}\left[\mathrm{f}^{-1}\left(\mathrm{~B}_{\mathrm{T}}\right)\right] \\
& =\mathrm{N}\left(\frac{\ln \mathrm{B}_{\mathrm{T}}-\ln \mathrm{A}_{\mathrm{T}}-\mu \mathrm{T}+\frac{1}{2} \sigma^{2} \mathrm{~T}}{\sigma \sqrt{\mathrm{T}}}\right)
\end{aligned}
$$

地方政府债券到期时的违约距离为:

$$
\mathrm{DD}=\frac{\ln \mathrm{A}_{\mathrm{T}}-\ln \mathrm{B}_{\mathrm{T}}+\mu \mathrm{T}-\frac{1}{2} \sigma^{2} \mathrm{~T}}{\sigma \sqrt{\mathrm{T}}}
$$

\section{3. 实证分析}

\section{1. 上海市财政收入预测}

选取 1978-2016 年上海市地方财政收入（FN）的历史数据作为本文研究对象，选用时间 序列方法中的 ARIMA 模型对上海市 2017 至 2022 年的地方财政收入进行预测。考虑到原始数 据数值较大, 序列平稳性较差, 导致序列的波动较大, 造成预测值误差增大, 因此, 首先对 原始数据取自然对数, ADF 单位根检验结果如下:

表 1. ADF 单位根检验结果

\begin{tabular}{|c|c|c|c|c|c|c|c|}
\hline 变量 & $\begin{array}{c}\text { 检验类型 } \\
(\mathrm{c}, \mathrm{t}, \mathrm{k})\end{array}$ & $\begin{array}{c}\mathrm{ADF} \\
\text { 统计量 }\end{array}$ & $\begin{array}{c}1 \% \\
\text { 临界值 }\end{array}$ & $\begin{array}{c}5 \% \\
\text { 临界值 }\end{array}$ & $\begin{array}{c}10 \% \\
\text { 临界值 }\end{array}$ & P值 & 结论 \\
\hline LNFN & $(\mathrm{c}, \mathrm{t}, \mathrm{1})$ & -1.857 & -4.219 & -3.533 & -3.198 & 0.657 & 不平稳 \\
\hline DLNFN & $(\mathrm{c}, \mathrm{n}, \mathrm{1})$ & -5.123 & -3.621 & -2.943 & -2.610 & 0.000 & 平稳 \\
\hline
\end{tabular}
势。

注: 检验类型 $(c, t, k)$ 中的 $c$ 是截距， $t$ 是时间趋势， $k$ 是滞后阶数, $n$ 是不含截距或时间趋

$\mathrm{ADF}$ 单位根检验结果显示, LNFN不是平稳序列, 一阶差分后序列是平稳序列。作图发现, LNFN序列在1994年之前变化较为平缓, 在1994年之后增长迅速, 反映出两段序列的截距和斜 率有所不同。为了提高预测精度, 本文引入两个虚拟变量, 其中在1994年（含1994）的数据 的虚拟变量为dum1, 1994年之后的数据的虚拟变量为dum2, 又因为LNFN序列含有自相关, 所以, 采用截距和结构双变动的模型预测LNFN是较为合适的。回归结果如下:

LNFN

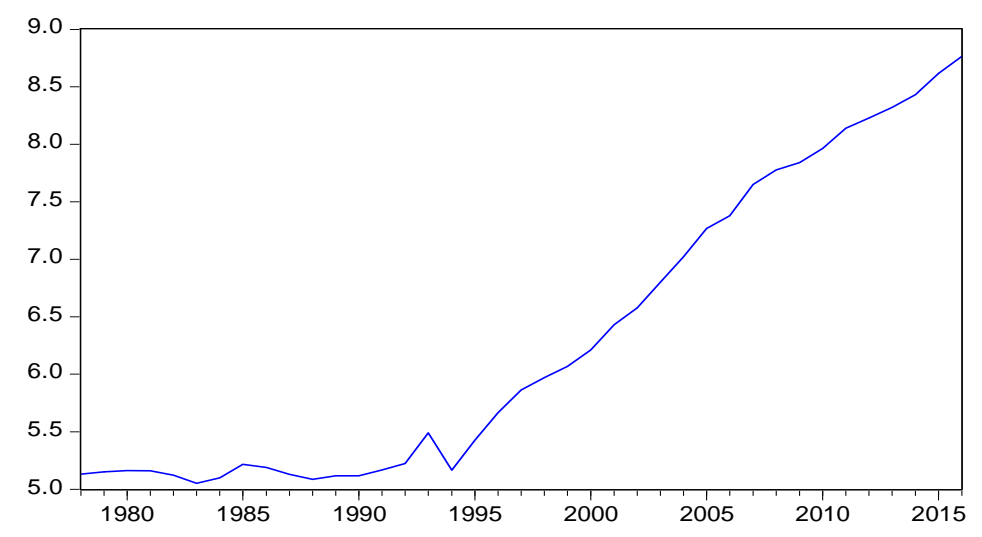

$$
\begin{aligned}
\operatorname{LNFN}_{t}= & 4.529 * \operatorname{dum} 1+0.366 * \operatorname{dum} 2+0.124 * \operatorname{dum} 1 * \mathrm{LNFN}_{t-1} \\
& +0.972 * \operatorname{dum} 2 * \mathrm{LNFN}_{t-1}+\mathrm{e}_{t}-0.365 \mathrm{e}_{t-5}
\end{aligned}
$$


表2 回归结果

\begin{tabular}{|l|c|c|c|c|}
\hline 变量 & 回归系数 & 标准差 & t值 & P值 \\
\hline DUM1 & 4.529 & 1.020 & 4.440 & 0.000 \\
\hline DUM2 & 0.366 & 0.097 & 3.790 & 0.001 \\
\hline DUM1*LNA (-1) & 0.124 & 0.198 & 0.628 & 0.535 \\
\hline DUM2*LNA (-1) & 0.972 & 0.014 & 71.446 & 0.000 \\
\hline AR (5) & -0.365 & 0.177 & -2.062 & 0.049 \\
\hline R-squared & \multicolumn{4}{|c|}{0.997} \\
\hline Ad justed R-squared & \multicolumn{4}{|c|}{0.996} \\
\hline Durbin-Watson stat & \multicolumn{4}{|c|}{1.951} \\
\hline
\end{tabular}

模型拟合优度为 0.997 , 很接近 1 , 托宾值为 1.951 , 接近 2 , 表明模型拟合效果很优, 尤其是拟合优度非常高, 适宜用来预测, 并得到 2017 至 2022 年的财政收入预测值分别为 7215. 51 亿、8100.01 亿、9063. 37 亿、10109. 25 亿、11241.21 亿和 12462.60 亿。

根据公式（计算增长率均值和波动率的公式）得出上海地方财政收入的增长率均值和波 动率如下:

表3 增长率均值和波动率

\begin{tabular}{|c|c|c|}
\hline 年份 & 增长率均值 & 波动率 \\
\hline 2018 & 0.1029 & 0.1204 \\
\hline 2020 & 0.0347 & 0.0661 \\
\hline 2022 & 0.0209 & 0.0500 \\
\hline
\end{tabular}

\section{2. 可担保比例确定}

地方政府财政收入不可能全部用于为地方债务做担保，需要采用扣除地方政府必要性财 政支出后的财政收入作为KMV模型中的变量。根据公共支出理论, 地方政府的必要性支出一般 由地方政府的公共服务、公共安全、医疗卫生、教育、社会保障和就业等公共方面的支出组 成, 观察2012年至2016年的上海市地方政府财政支出的数据, 我们发现2012年至2016年上海 市政府必要性支出占北京市地方公共财政收入的比例均在 $70 \%$ 左右, 因此, 基于30\%的担保比 例, 由上述2017-2022年财政收入预测值, 可以计算得出2018年、2020年和2022年的担保额度 为 2430 亿、3063.92亿和3903.90亿。

3.3. 违约概率计算

政府发行债券的期限一般为 1 年期、3 年期和 5 年期, 本文主要研究上海市政在 2017 年 如果发行这三种方式的地方政府债券, 即发行 1 年期的将在 2018 年偿还, 发行 3 年期的将在 2020 年偿还，发行 5 年期的将在 2022 年偿还，接下来将计算不同期限品种对应的违约率。

将增长率均值、波动率和担保额度带入计算违约率的公式, 既可得出上海市地方政府 2017 年发行不同规模债券对应的违约率。 
表4 发债规模和违约概率

\begin{tabular}{|c|c|c|c|c|c|c|c|c|c|}
\hline & \multicolumn{3}{|c|}{$\mathrm{T}=1$} & \multicolumn{3}{|c|}{$\mathrm{T}=3$} & \multicolumn{3}{|c|}{$\mathrm{T}=5$} \\
\hline $\begin{array}{l}\text { 发债 } \\
\text { 规模 } \\
\text { 占可 } \\
\text { 担保 } \\
\text { 比例 }\end{array}$ & $\begin{array}{c}\text { 发行规 } \\
\text { 模 }\end{array}$ & $\begin{array}{c}\text { 违约距 } \\
\text { 离 }\end{array}$ & 违约概率 & $\begin{array}{c}\text { 发行规 } \\
\text { 模 }\end{array}$ & $\begin{array}{c}\text { 违约距 } \\
\text { 离 }\end{array}$ & 违约概率 & $\begin{array}{c}\text { 发行规 } \\
\text { 模 }\end{array}$ & $\begin{array}{c}\text { 违约距 } \\
\text { 离 }\end{array}$ & 违约概率 \\
\hline 0.10 & 243.00 & 19.917 & $1.46 \mathrm{E}-88$ & 306.39 & 20.951 & $2.01 \mathrm{E}-102$ & 380.39 & 21.456 & $2.01 \mathrm{E}-102$ \\
\hline 0.15 & 364.50 & 16.549 & $8.10 \mathrm{E}-62$ & 459.59 & 17.412 & $1.99 \mathrm{E}-71$ & 570.59 & 17.832 & $1.99 \mathrm{E}-71$ \\
\hline 0.20 & 486.00 & 14.160 & $8.08 \mathrm{E}-46$ & 612.78 & 14.901 & $6.95 \mathrm{E}-53$ & 760.78 & 15.261 & $6.95 \mathrm{E}-53$ \\
\hline 0.25 & 607.50 & 12.307 & $4.15 \mathrm{E}-35$ & 765.98 & 12.953 & $1.81 \mathrm{E}-40$ & 950.98 & 13.267 & $1.81 \mathrm{E}-40$ \\
\hline 0.30 & 729.00 & 10.793 & $1.86 \mathrm{E}-27$ & 919.18 & 11.361 & 1. $33 \mathrm{E}-31$ & 1141.17 & 11.637 & 1. $33 \mathrm{E}-31$ \\
\hline 0.35 & 850.50 & 9.513 & $9.29 \mathrm{E}-22$ & 1072.37 & 10.016 & $5.36 \mathrm{E}-25$ & 1331.37 & 10.260 & $5.36 \mathrm{E}-25$ \\
\hline 0.40 & 972.00 & 8.404 & 2. $16 \mathrm{E}-17$ & 1225.57 & 8.850 & 6. $17 \mathrm{E}-20$ & 1521.56 & 9.066 & $6.17 \mathrm{E}-20$ \\
\hline 0.45 & 1093.50 & 7.426 & $5.61 \mathrm{E}-14$ & 1378.77 & 7.822 & $5.58 \mathrm{E}-16$ & 1711.76 & 8.013 & $5.58 \mathrm{E}-16$ \\
\hline 0.50 & 1215.00 & 6.551 & $2.87 \mathrm{E}-11$ & 1531.96 & 6.903 & $7.65 \mathrm{E}-13$ & 1901.95 & 7.072 & $7.65 \mathrm{E}-13$ \\
\hline 0.55 & 1336.50 & 5.759 & 4. $23 \mathrm{E}-09$ & 1685.16 & 6. 071 & 2. $49 \mathrm{E}-10$ & 2092.15 & 6.220 & $2.49 \mathrm{E}-10$ \\
\hline 0.60 & 1458.00 & 5.036 & $2.37 \mathrm{E}-07$ & 1838.35 & 5.311 & $2.63 \mathrm{E}-08$ & 2282.34 & 5.442 & $2.63 \mathrm{E}-08$ \\
\hline 0.65 & 1579.50 & 4. 372 & 0.000006 & 1991.55 & 4. 612 & 0.000001 & 2472.54 & 4.727 & 0.000001 \\
\hline 0.70 & 1701.00 & 3.756 & 0.000086 & 2144.75 & 3.966 & 0.000024 & 2662.73 & 4.065 & 0.000024 \\
\hline 0.75 & 1822.50 & 3.183 & 0.000728 & 2297.94 & 3.363 & 0.000282 & 2852.93 & 3.448 & 0.000282 \\
\hline 0.80 & 1944.00 & 2.647 & 0.004057 & 2451.14 & 2.800 & 0.002045 & 3043.12 & 2.871 & 0.002045 \\
\hline 0.85 & 2065.50 & 2.144 & 0.016023 & 2604.34 & 2.271 & 0.009922 & 3233.32 & 2.329 & 0.009922 \\
\hline 0.90 & 2187.00 & 1.669 & 0.047544 & 2757.53 & 1.772 & 0.034498 & 3423.51 & 1.818 & 0.034498 \\
\hline 0.95 & 2308.50 & 1.220 & 0.111207 & 2910.73 & 1.300 & 0.090901 & 3613.71 & 1.335 & 0.090901 \\
\hline
\end{tabular}

3. 4. 实证结果

当发行规模在可担保比例的 70\%以内时，即 1 年期的发行规模在 1700 亿以内，3 年期发 行期规模在 2144.75 亿以内, 5 年期发行期规模在 2662.73 亿以内时, 无论发行期限为 1 年, 还是 3 年, 或 5 年, 违约概率接近 0 , 非常低。在对数正态分布情况下, 地方政府债券违约 概率随着发债规模扩大而迅速提升，即违约概率对发债规模具有高度敏感性。

为了找到具体的安全发债规模，需要先确定地方政府债券的违约概率的临界值。通常借 鉴美国标准普尔和穆迪的标准，美国市政债的违约率临界值大约为 $0.4 \%$ ，一般认为，违约 概率低于 $0.4 \%$ 的市政债券的发行规模是在安全范围内的。如果采取 $0.4 \%$ 的临界值， 1 年期 的发行规模介于 1822 亿和 1944 亿之间, 可推算得到约为 1942.91 亿, 同理, 3 年期和 5 年 期最优发债规模分别为 2493.12 亿和 3118.82 亿。

考虑到我国地方政府债券正处于起步阶段，地方政府债券市场尚不完善，相关法律制度 仍在准备阶段, 地方政府预算软约束等种种因素, 使我国地方政府债券市场与美国市政债市 场的市场化程度相差甚远，因此取 $0.2 \%$ 作为我国地方政府债券的违约率临界值，1年期、3 年期和 5 年期最优发债规模分别为 1890.74 亿、2429. 39 亿和 3040.84 亿, 大约占担保比例 的 77. $81 \%$ 79. 29\%和 79.94\%, 分别占 2018 年、2020 年和 2022 年的 $22.485 \% 、 23.79 \%$ 和 $23.98 \%$ 。

中国政府短期内发生债务危机的概率很小。但随着经济增长下行压力加大, 在经济体负 债率不断提高的同时, 企业利润缩水、偿债能力减弱, 不良债务率也在提升。根据修正的 KMV 模型，地方政府债券发行是以城市政府可担保财政收入作抵押的，上海政府应当充分考虑到 未来财政收入变化和偿债能力来确定发行规模, 切不可为了加快本地区经济发展和城市建设 而盲目发债，引发信用风险。当下政府债务状况虽然良好，但仍需关注并严密控制重点局部 和薄弱环节的债务风险, 以防债务问题影响实体经济的平稳运行。 


\section{4. 政策建议}

\section{1. 提升地方政府债券的流动性}

地方债相对于国债和政策性银行债发行规模往往比较小，所以二级市场交易不太活跃。 从回购质押的角度来看, 地方债的回购融资能力远低于国债和政策性银行债。因此, 应提升 地方债二级市场流动性, 进一步完善做市商制度, 打通银行间和交易所市场, 让更多投资者 参与二级市场交易。推动地方政府、金融机构、中介机构按照市场化原则充分竞争，进一步 提高地方债发行定价市场化水平。另外，通过一些税收优惠政策，引导社保基金、住房公积 金、保险公司等机构投资者和个人投资者等积极投资地方政府债券，加大地方债券投资力度。 4. 2. 完善我国地方政府债券的信用评级制度

2015 年我国已初步建立了地方政府债券的信用评级制度, 我国 34 个有权发债的省、自 治区、直辖市和计划单列市政府债券均获 AAA 评级, 地方债评级的虚高让我们对信用评级是 否真的能发挥作用产生疑惑。信用评级机构是融资体系中的重要一环，对于地方债券市场的 有序发展起到了推动作用。但目前我国绝大多数评级机构在开展信用评级过程中受到行政干 预较多, 评级机构和发债政府之间因利益关系导致的评级结果缺乏公信度。因此, 一方面要 提高地方政府的公信力、信息透明度, 使评级机构能得到充足的信息, 另一方面, 应提高信 用评级机构的独立性、专业性和社会公信力, 并鼓励评级机构良性竞争, 由各类新闻媒体公 开监督, 保证信用评级结果的可信度。

\section{3. 建立健全风险预警和考核问责等机制}

中央政府应督促地方政府切实履行偿债责任, 妥善处理存量债务, 加大力度惩处地方政 府违法违规举债担保行为。中央政府还需完善地方政府发债的检测指标。对低投资回报率、 高债务率的政府公共基础建设, 应积极采取多种措施化解其债务风险。通过政府债务限额管 理和预算管理, 控制政府债务规模, 如制定中长期滚动预算, 在跨年度的时间框架内, 根据 各种政策和环境变化预估支出的中长期影响和未来成本, 对或有负债需进行提前预估与测算, 从而进行远期风险控制。有些地方政府官员存在任内大规模举债建设, 偿债风险丢给后任的 做法, 因此, 应将考核问责落到实位, 属于任内举债形成的风险事件的, 在终止应急措施之 前, 政府官员不得重用或提拔; 属于已经离任的政府领导责任的, 应当依法追究其责任。

4. 4. 明确地方政府债务的偿还与救援机制

2016 年 11 月 11 日国务院办公厅出台《地方政府性债务风险应急处置预案》。这份文件 中最核心的一条是：“地方政府对其举借的债务负有偿还责任, 中央实行不救助原则。” 我 国应明确不同债务对应的事权和支出责任, 合理划分中央和地方债务的事权和支出责任, 明 确界定上下级财政部门的债务责任范围。属于中央事权、但由地方负债融资的项目应该由中 央财政偿还; 属于地方事权的项目, 则由地方政府负责举债, 并应明确地方偿还所对应的税 种或者特定项目的收益。本级政府的债务责任应由本级政府负责承担, 地方政府不得存在中 央对债务拖底的幻想。

\section{5. 建全地方政府债券发行的信息披露制度}

信用评级机构进行信用评级需要大量基础数据和公开信息, 但目前地方政府在财政预算、 预算外收支、资产负债等方面存在信息不透明、不全面的问题。评级机构在地方政府债券评 级中得到的主要是一些流量数据, 如 GDP、财政收入等, 缺少政府资产、负债等存量方面的 数据, 并且地方政府向人大提交的债务信息大多只有新增债务、置换债务、余额限额等总量 数据, 缺少债务资金支出的具体项目、偿债计划、限额确定机制等详细内容。因此, 我国地 方政府应尽快完善规范化的信息公开披露机制, 合理规定地方政府地方债券的披露内容、途 径和方式, 这是化解地方债务风险、发展地方经济的基础条件。在披露的内容上, 应提高地 方政府资产负债综合财务报告、财政预决算报告、审计报告、融资概要、债券发行材料披露 的及时性与透明度。在披露的途径和方式上, 地方政府应尽快建立公开、透明的地方政府财 务信息库，对债券的规模、类型、偿还情况等具体说明，供财政部门、金融机构和公众查询。 


\section{6. 制止地方政府违法违规融资担保行为}

根据预算法、担保法等规定, 除外债转贷担保外, 地方政府不得为任何债务提供担保, 然而各地违法违规担保举债现象仍难以遏制。在当前中国经济下行的背景下，许多地方政府 靠举债来保持高投资、大建设，一些地方 PPP 项目以财政资金作为风险自底的劣后资金，这 实质上是地方政府变相举债。通过政策性贷款等方式为基建项目融资时，金融机构要求地方 政府为企业平台提供担保承诺来转移金融机构经营风险, 这加剧了地方政府债务风险。因此, 应健全地方政府债务管理制度，一方面继续发行地方政府债券置换存量债务。减轻地方政府 利息负担, 缓解地方偿债压力; 另一方面坚决制止地方政府违法违规融资担保行为, 堵住各 种不规范渠道，加大对地方政府债务的监督、查处和曝光力度，切实防范化解财政金融风险。

\section{References}

[1]. Lei Zhang. Measurement of the affordability of local government debt based on KMV model : a case study of nine provinces in the Pearl River Delta. Zhejiang Finance, 2016(7):10-15.

[2]. Yinjie Deng, Danyun Hu. Measurement of credit risk of local government bonds based on KMV model: a case study of Beijing government bonds. Modern Economic Information, 2015(24):476-478.

[3]. Gang Wang, Liyan Han. Research on Risk Prevention and Control in China 's Municipal Bond Management. Journal of Finance and Economics, 2003(7):1

[4]. Haixing Zhang, Weifeng Jing. Research on credit risk measurement and safe issue-volume of local government bonds - a case study of ten Provinces and cities based on KMV model. Macro Economic Research, 2016 (5):48-60 